\title{
Measurement of Exhaled Nitric Oxide Using End Tidal Value during Normal Breathing
}

Tawfic S Hakim ${ }^{1,2 *}$, George Cremona ${ }^{1,2}$ and Enrico Camporesi ${ }^{1,2}$

${ }^{1}$ Division of Sleep Disorders, Phoenix, AZ, Instituto Scientifico San Raffaele, Milan, Italy

${ }^{2}$ University of South Florida, Tampa Florida, USA

\begin{abstract}
Increased nitric oxide (NO) production in the expired air has been associated with a number of disease conditions and may reflect the severity of inflammation in the lungs. Measurement of exhaled NO concentration has been proposed as a novel clinical tool for assessing airway inflammation and response to drug therapy. In spite of international guidelines aimed at standardizing the measurement of exhaled NO, clinicians remain skeptical due to the necessity of a significant degree of subject collaboration required by the procedure to obtain meaningful measurements. We hypothesized that exhaled NO concentration may be best measured by using end tidal NO concentration during a breath by breath monitoring. We tested laboratory staff and monitored their NO concentration online using a fast response chemiluminescence NO analyzer during normal breathing at rest for 5 minutes. First we confirmed that the $\mathrm{NO}$ analyzer was adequately fast to record fully the swings during normal breathing. We then compared the average end tidal NO value (NOet) from 6 to 10 breaths, to the NO value obtained from the plateau from a single slow vital capacity maneuver as recommended by the ATS guidelines (NOplat). End of exhalation was identified using end tidal carbon dioxide measurement. NOet while breathing room air was $24.3 \pm 4.2$ (SE) ppb and was not significantly different compared to $22.4 \pm 2.8$ (SE) ppb using NOplat. Additionally breathing high level of NO of up to $88 \mathrm{ppb}$ did not affect either NOet or NOplat significantly suggesting that both measurements are independent of inhaled NO concentration. $\mathrm{NO}$ value at end of exhalation was very reproducible from breath to breath and did not require any special effort on the part of the subject. We recommend using NOet measurement instead of the NOplat value that is highly dependent on the exhalation rate and cooperation of the subject. NOet is much easier to record in children, elderly and patients with respiratory disease. The main requirement for measuring NOet is to have a fast response NO analyzer to record the full swings in NO concentration during normal breathing and to have a way of identifying end exhalation.
\end{abstract}

Keywords: Exhaled nitric oxide; Tidal breathing; Single breath; Human

\section{Introduction}

Nitric oxide (NO) has been detected in the exhaled gas of humans and animals [1]. The level of NO in exhaled gas has been shown to increase in certain states of lung inflammation $[2,3]$ and has been suggested as a new clinical test [4]. Indeed, Exhaled NO has been widely used in asthma as a measure of severity of inflammation in the lungs [5] and in the management during drug therapy [6,7]. NO is produced by many cells in the lung and is released into the airspace including airways and alveoli [8-10]. Having both alveolar and airway components, the manner used to measure exhaled NO can affect the outcome and continues to be a subject for debate [11]. Recognizing that the measurement is flow dependent, current guidelines recommend a slow vital capacity maneuver at a fixed flow rate of $50 \mathrm{ml} / \mathrm{sec}$ against a resistance [12-14] which is a compromise between measurement sensitivity and patient comfort. While this method has been reluctantly adopted by many, it may be biased against detection of NO in the alveolar space and has been shown to be difficult to measure in some situations especially those involving children or uncooperative subjects [15].

The guidelines were recommended to create uniformity in measuring and reporting exhaled $\mathrm{NO}$ and not to preclude other valid methods for measuring NO. The guidelines correctly emphasized that the recommendations should not necessarily invalidate other sensible and reasonable methods. Whether these recommendations have helped in bringing about some uniformity and more reliable application of NO measurement is not clear but disagreements remain after so many years [16-19]. Furthermore, the guidelines have justifiably influenced the industry and some companies have manufactured NO analyzers narrowly based on the guidelines, potentially hindering the development of better methods for NO measurement. While some clinicians remain skeptical about using NO measurement [16-19], others believe the measurement is very useful and helps with the management of asthma [6,20-22]. More importantly, the changes in NO concentration in exhaled air in lung diseases can be small and subtle and can be easily overshadowed by methodological errors, such variations as in flow rate or patient's cooperation. Therefore it is prudent that we use a reliable method to measure exhaled $\mathrm{NO}$ as a meaningful clinical tool. Our goal was to show that exhaled $\mathrm{NO}$ can be easily and more reliably assessed using end tidal NO concentration.

\section{Material and Methods}

Males and females volunteers $(n=19)$ ranging from 27 to 52 yrs in age, and in good health were invited to participate in the study. The volunteers were laboratory personnel. The study was approved by the Institutional Review Board and a consent form was signed by all volunteers. None of the subjects had any symptoms of respiratory tract infection and none were habitual smokers.

\section{Protocol of the study}

Figure 1 shows a diagram of the set up that was used for the study. The subject was seated in a comfortable chair, and the mouthpiece was

*Corresponding author: Tawfic S Hakim, Division of Sleep Disorders, Phoenix AZ, Instituto Scientifico San Raffaele, Milan, Italy, Tel: 602-944-0847; Fax: 602944-1014; E-mail: salthakim@yahoo.com

Received October 03, 2014; Accepted November 10, 2014; Published November 14,2014

Citation: Hakim TS, Cremona G, Camporesi E (2014) Measurement of Exhaled Nitric Oxide Using End Tidal Value during Normal Breathing. J Pulm Respir Med 4 219. doi:10.4172/2161-105X.1000219

Copyright: $\odot 2014$ Hakim TS, et al. This is an open-access article distributed under the terms of the Creative Commons Attribution License, which permits unrestricted use, distribution, and reproduction in any medium, provided the original author and source are credited. 


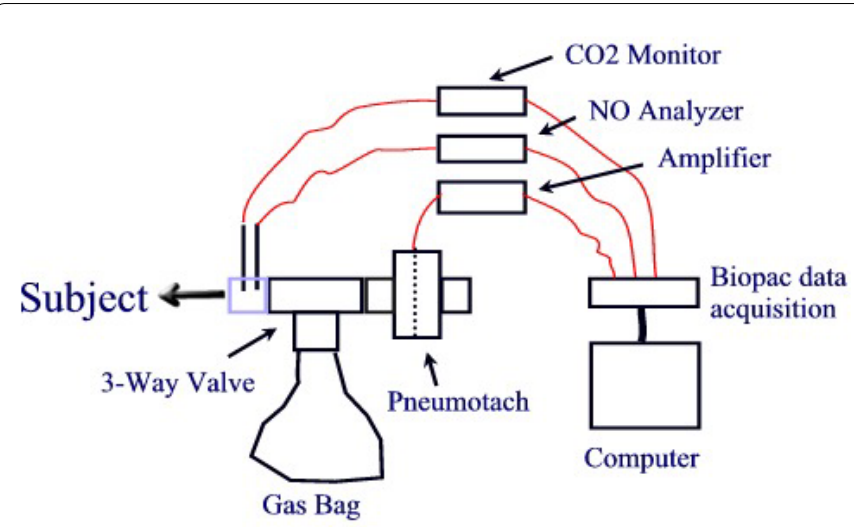

Figure 1: Experimental set up that was used. The 3 way valve allowed the subject to inhale from the bag and exhale through the pneumotach.

adjusted for easy reach by the subject. The subject breathed through the mouth (with a nose clip) through a disposable mouthpiece connected to a 3 way valve and a pneumotach (Biopac Systems TSD 117). This set up allowed inhalation from the bag and expiration through the pneumotach while sampling gas continuously from side ports near the mouthpiece for $\mathrm{CO} 2$ and $\mathrm{NO}$ measurement. $\mathrm{NO}$ was measured using a fast response chemilumiscenece NO analyzer (Sievers 270B, Boulder, $\mathrm{CO}$ ) and $\mathrm{CO} 2$ was measure using a CO2 monitor (Datex Ohmeda, Madison, WI). The inspiratory limb of the 3 way valve was either open to room air or was connected to one of the bags that contained a known concentration of NO (up to $88 \mathrm{ppb}$ ). Gas was sampled into the NO analyzer at $400 \mathrm{ml} / \mathrm{min}$. The signals from the $\mathrm{NO}$ analyzer and $\mathrm{CO} 2$ monitor as well as the pneumotach were fed into a computer for continuous breath by breath recording and observation. The analog signals were digitized at $10 \mathrm{HZ}$ aligned and stored continuously on a Macintosh computer using data acquisition software (MP100 BIOPAC Systems, Goleta, CA). The output from the NO analyzer was recorded continuously and displayed as ppb. The average NO concentration from 0.5 to $1 \mathrm{sec}$ of data near end expiration was measured and the values from a few breaths ( $5-10$ breaths) was used as end tidal NO concentration (NOet). Calibration of the NO analyzer was performed daily and zero was verified repeatedly during the experiment. Room air $\mathrm{NO}$ was also recorded repeatedly during the experiment. The linearity of the NO analyzer was verified by diluting NO sample serially 4 times down to $10 \mathrm{ppb}$. One group of subjects were studied to compare end tidal NO while breathing different levels of $\mathrm{NO}$, and a second group were studied to compare end tidal NO with the plateau NO value derived from the single breath method as suggested by the ATS/ERS guidelines. The two groups were studied on separate days. Some of the subjects that were used in group one, were also used in group two.

In the first group the subjects were asked to breathe normally with the 3 way valve open to room air. Once the subject was relaxed, recording began for about 5 to $10 \mathrm{~min}$. Breathing was then switched to the next bag with the higher concentration for another 5 to $10 \mathrm{~min}$, and so on with the other NO bag mixtures (described below). This part of the study was designed to test the adequacy of the response time of the NO analyzer during normal breathing. In the second group, the subjects were asked to breathe room air for 5 minutes, at the end of which the subject was asked to take a deep breath, and exhale slowly at a rate of $50 \mathrm{ml} / \mathrm{s}$ until all the air is expelled. The plateau near the end of expiration was used to measure NO concentration (this maneuver was done to reproduce the procedure that was recommended by the ATS guidelines). After a short break, the procedure was repeated, while breathing from the bags with the higher NO concentrations. This was repeated for the other bags containing higher NO concentrations. The single slow expired breath maneuver was done only once in each case to record plateau NO level from a single breath (NOplat), no resistance was used, and a nose clip was present.

The analyzer was calibrated daily by introducing air with zero NO from a gas cylinder and from a mixed gas bag containing $248 \mathrm{ppb}$ which was prepared from a certified gas tank containing $1424 \mathrm{ppb}$ NO in pure air (MG Industries, Valley Forge, PA). The gas concentration was diluted to $248 \mathrm{ppb}$ for calibration. The gas bags were prepared by filling them with a known volume of air from a tank of medical grade compressed air using a $5 \mathrm{~L}$ syringe. A small volume of the certified nitric oxide gas mixture was added using a $50 \mathrm{cc}$ glass syringe. There were 3 or 4 bags with different levels of $\mathrm{NO}$ of up to $80 \mathrm{ppb}$ ready for use. Room air NO concentration was monitored daily, and when it exceeded $5 \mathrm{ppb}$, the subject breathed from a bag containing room air with zero NO from a compressed gas tank (was necessary in 1 of the 13 subjects). The bags were prepared shortly before the experiment started. The bags contained NO with a calculated concentration of $0,24.9,47.8,80.3 \mathrm{ppb}$ NO. The concentration of NO in the bag was measured offline after it was prepared and was usually within $5 \%$ from the calculated value. We selected these concentrations because they are safe, and represent the range of variations in $\mathrm{NO}$ in ambient air in our facility.

Statistical analysis of the results was accomplished using ANOVA for repeated measures and post hoc t-test (Boneforroni test). All results are expressed as means \pm SEM. Relationship between NOet and NOplat, was also examined using a linear regression analysis. $\mathrm{P}$ values of $<0.05$ were considered significant.

\section{Results}

A typical recording from one subject in the first group with the different levels of inhaled NO (NOi) is shown in Figure 2. Note the breath to breath consistency in $\mathrm{NO}$ at end expiration (NOet) during normal breathing regardless of the level of inhaled NO. End tidal NO was nearly identical from one breath to another (arrows). Furthermore, peak NO during inspiration was very close to NO in the bag suggesting that the response of the analyzer was adequate to record with accuracy inhaled and exhaled NO concentration during normal breathing. End tidal NO (arrows) remained unchanged while breathing different levels of NO. On a tracing like this, it would have been difficult to be certain which peak is end expiration without the $\mathrm{CO} 2$ tracing being available simultaneously.

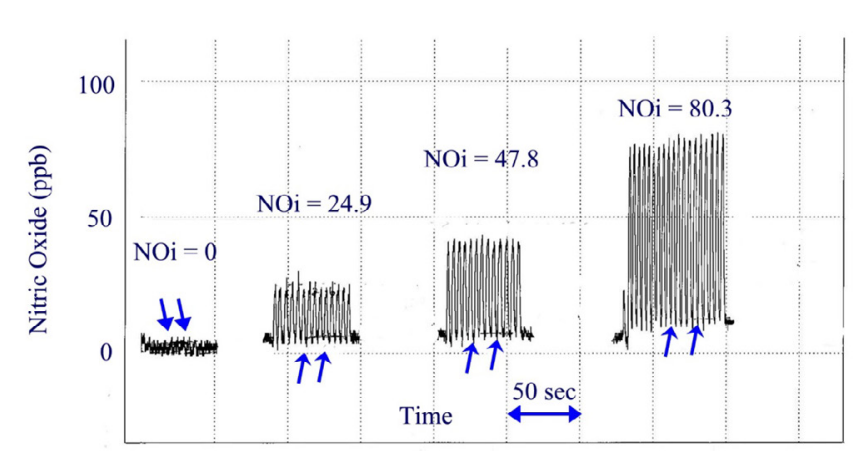

Figure 2: Tracing of NO during normal breathing. Inhaled NO in the bag is indicated (NOi) and arrows point to the tracing at end expiration. With room air $(\mathrm{NO}=0)$ end expiration is on the top of the tracing. In contrast, during breathing high NO mixture, end expiration is near the bottom of the tracings. Note the consistent value at end expiration for all breaths. 
An expanded view of few breaths showing $\mathrm{CO} 2$ and $\mathrm{NO}$ is shown in Figure 3. Regardless of the level of inhaled NO or the shape of NO peak at the start of expiration, end tidal NO concentration, identified from $\mathrm{CO} 2$ tracing was easily quantified. In this example, the subject had very low end tidal NO. CO2 recording was helpful to identify a stretch $(0.5$ to $1 \mathrm{sec})$ of data that could be averaged and would represent end tidal NO value for each breath. Peak value during inspiration was usually within $5 \%$ of the bag calculated value, and was somewhat difficult to read because there was no delay or a plateau compared to end expiration where NO level was flat for 1 to 2 seconds. The shape of NO tracing varied among subjects while breathing room air, some exhibited an early peak that may have been related to contamination from nasal NO. The concentration at end expiration could be easily identified and averaged over 0.5 to 1 second of data with the aid of the $\mathrm{CO} 2$ tracing. The values from 5 to 10 breaths were averaged to represent NOet for the subject.

There was a wide range in NOet values ( $0.2 \mathrm{ppb}$ to $53 \mathrm{ppb})$ among the subjects. In the first group of subjects, average NOet was $15.4 \pm 2.2$ $\mathrm{ppb}( \pm \mathrm{SE}$ ) when the subjects breathed room air, and did not change significantly when they breathed from the bags containing higher NO concentrations (Figure 4). While breathing from the bag with high $\mathrm{NO}$, NOet was $15.3 \pm 2.1 \mathrm{ppb}, 16.3 \pm 2.0 \mathrm{ppb}$, and $16.5 \pm 1.8 \mathrm{ppb}$ respectively and were not significantly different from each other $(P>0.4)$. End inspired NO was not significantly different from the NO in the bag $(\mathrm{P}>0.1)$, suggesting that the $\mathrm{NO}$ analyzer had an adequate response time to record accurately the full swings in NO concentration during normal breathing.

In the second group of subjects, NOet and in NOplat, also exhibited a wide range among the subjects, 0.2 to $53 \mathrm{ppb}$ and 7 to $43 \mathrm{ppb}$ respectively. As stated earlier, some of the subjects used in group 1 were

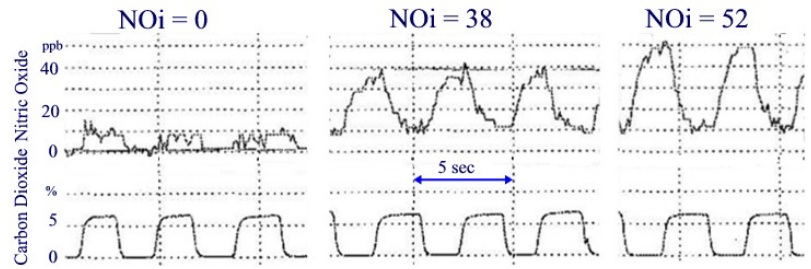

Figure 3: Expanded view of the $\mathrm{NO}$ tracings along with $\mathrm{CO}_{2}$ tracing. End tidal $\mathrm{NO}$ was the average over 1 to 2 seconds during the time when $\mathrm{CO}_{2}$ was plateau at peak value. The average of 5 to 10 breaths was used as NOet. Inhaled NO (NOi) is given during each segment of the tracing.

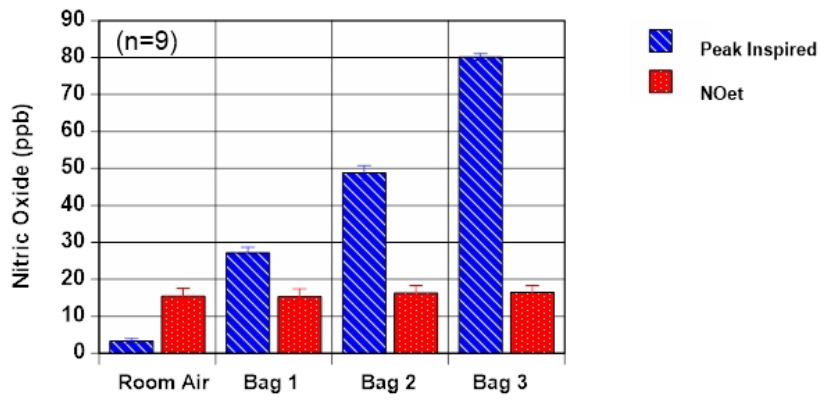

Figure 4: Average end tidal NO (NOet) during breathing room air and breathing high NO mixture. Peak NO during inspiration was very close to NO concentration in the bag. NOet did not change and was independent of inhaled $\mathrm{NO}(\mathrm{P}>0.4)$

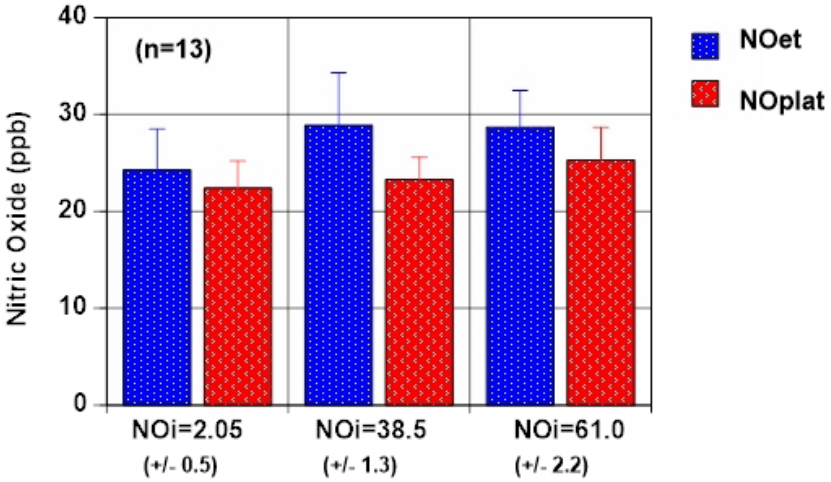

Figure 5: NOet versus NOplat as measured using the single breath exhalation according to the ATS guidelines. There were small differences that were not significant $(P>0.4)$. Both NOet and NOplat were independent of inhaled NO $(\mathrm{P}>0.4)$.

also inlcuded in this group. Average NOet vs NOplat are compared in Figure 5. This group of subjects breathed either room air $(\mathrm{NOi}=2.1 \pm$ $0.5 \mathrm{ppb}$ ) or from a bag containing $38.5 \pm 1.3 \mathrm{ppb}$ and a bag containing $61.2 \pm 2.2 \mathrm{ppb}$. NOet was $24.3 \pm 4.2,28.9 \pm 5.4$, and $28.7 \pm 3.8 \mathrm{ppb}$ respectively while NOplat was $22.4 \pm 2.8,23.3 \pm 2.3 .25 .3 \pm 3.4 \mathrm{ppb}$ respectively. In either case the measured $\mathrm{NO}$ was independent of the inhaled NO concentration. Furthermore, NO measured with the two methods were not significantly different $(\mathrm{P}>0.4)$ from each other. The changes in NOet or NOplat while breathing high NO mixture were not statistically significant $(\mathrm{P}>0.4)$. The relationship between NOet and NOplat from linear regression analysis through the origin was NOplat $=0.78$ NOet $(\mathrm{R} 2=0.85)$.

\section{Discussion}

In this study we found that exhaled $\mathrm{NO}$ measured from $\mathrm{NO}$ value at end expiration during normal tidal breathing (NOet) was not significantly different from that measured from the single slow vital capacity maneuver $[13,14]$ but was much easier to perform. Measurement of NOet required no special instructions and no extra effort from the subject. The subjects were simply asked to breathe room air normally for a few minutes. Furthermore, NOet was independent of inhaled NO within the normal environmental range suggesting that day to day variations in ambient NO do not influence NOet measurement. Therefore, we suggest that monitoring breath by breath $\mathrm{NO}$ and using the average NOet concentration is preferred over NOplat, from the single breath method recommended by the ATS guidelines $[13,14]$. The single slow vital capacity maneuver was done using exhalation rate in the range that was recommended by the ATS guideline, however rate of exhalation can affect the measured NO value significantly. Thus the agreement between the two measured values is valid only for a specific flow rate that was used during the single slow full capacity maneuver. Although the limitations maybe different, both methods are likely to provide NO concentration representing NO production from the lungs that would have similar clinical and physiological implications. The main requirement for measuring NOet is having a NO analyzer with a response time fast enough to record swings in NO during tidal breathing, and a marker for identifying the end expiration time. The response time of our NO analyzer according to the manufacturer specification is $67 \mathrm{msec}$ to $90 \%$ full scale, which makes it very suitable for measuring end tidal NO during normal tidal breathing.

The main thrust of the ATS guidelines was to encourage uniformity 
in measuring and reporting exhaled $\mathrm{NO}$ values that took into account online measurement, flow dependence and potential nasal contamination [14]. While recognizing that NO measurement was highly dependent on flow rate used during exhalation, the slow vital capacity maneuver against a fixed resistance at a moderate flow rate, that was recommended, achieved an acceptable compromise while making the measurement easier. As such, children and non-collaborative subjects are yet often unable to perform these maneuvers [15] in spite of numerous visual feedback systems, thus limiting the reliability of the method. Equally, this maneuver, biased towards measurement of airway derived NO, has limited the widespread application of the measurement for conditions involving NO derived from a peripheral compartment such as the alveolar space. Complex procedures such as measurements at variable rates have been suggested $[23,24]$ which however made it even more difficult and lengthy. The single slow breath maneuver, requires taking a slow deep breath over 2 to 3 seconds. This may allow more NO in the alveolar space to diffuse into the blood, (to some extent similar to a breath hold) thus causing the measurement to underestimate alveolar NO concentration. Thus the slow full capacity maneuver against a resistance is somewhat subject to errors and maybe too difficult to perform especially for children and elderly. It also may be burdensome for patients with pulmonary disease, especially if they have to repeat the maneuver 2 or 3 times. NOet measurement avoids such problems and in our opinion, besides being easier, is a more reliable method for measuring exhaled NO for clinical purposes. Indeed, end tidal $\mathrm{CO} 2$ and $\mathrm{O} 2$ have been the gold standard for measuring gas concentration in the lungs for many years. End tidal NO value was stable over many breaths and much easier to identify. When necessary, changes in minute ventilation, which can affect exhaled NO concentration, can be accounted for by calculating NO production [25]. The effect of nasal contamination [26] on NOet measurement is likely to be very small during normal breathing because most of the $\mathrm{NO}$ would have been washed away early during expiration, and can be further minimized by applying a small negative pressure at the nose [27]. Nasal contamination may be more significant in other situations such as when measuring $\mathrm{NO}$ in mixed exhaled gas, measuring peak $\mathrm{NO}$, or breath holding where nasal NO can accumulate in the upper airways.

The ATS guidelines attempted to create a uniform method for measuring and reporting exhaled NO, however, investigators remain reluctant about the procedure, and have looked for other ways to measure exhaled NO [28-30]. Some studies compared the single breath measurement with measurement from mixed expired air during tidal breathing $[15,29,31]$. Mixed expired samples may be highly affected by $\mathrm{NO}$ in dead space (physiological and anatomical) or contamination by NO derived from ambient or nasal NO. Most studies found exhaled NO measured by the single breath method to be unaffected by inhaled/ environmental NO [32,33], as we did in this study. A direct comparison between the different methods found ambient NO to have an effect on mixed expired but not on single breath measurement [16,34]. In the present study, there was no obvious early peak in NO at the beginning of exhalation while breathing high NO concentrations; merely higher values because of the increased NO in large airways (Figure 3 ). The high $\mathrm{NO}$ in large airways under such condition will inevitably lead to higher NO concentrations in a mixed exhaled gas sample. In contrast, NOet was unaffected by inhaled NO level as was NOplat.

Nitric oxide in gas phase and in hemoglobin free solution is relatively stable [35], and any nitric oxide released by cells into the air space in the lungs, be it small airways, alveoli or large airways, is likely to linger for a few seconds and certainly long enough for the duration of a breathing cycle. A fraction of the nitric oxide in the alveoli is lost by diffusion into the blood and binding to hemoglobin, but a considerable fraction remains in the lungs and is eliminated in the exhaled air [27,34]. Therefore NOet could possibly represent air from the alveolar region of the lungs. Indeed, there is considerable evidence that the source of exhaled NO is from the alveolar region and small airways; it is detected in isolated lungs [36,37], in tracheostomized animals [2] and in human with bronchoscopy [27]. Persson et al. [38] showed that injection of nitroglycerine intravenously in rabbits lead to an increase in exhaled NO, further suggesting that exhaled $\mathrm{NO}$ comes from the alveolar region. Bortland et al. [39] concluded that NO detected in the exhaled air in human is produced in the alveolar region. In isolated pig lungs, Cremona et al. [37] found increased exhaled NO after intravenous acetylcholine and decreased $\mathrm{NO}$ when blood was added to the perfusate suggesting that $\mathrm{NO}$ is produced in the alveolar region. Tsujino et al. [27] and Corradi et al. [34] also found that in healthy subjects the last portion of the breath (mostly alveolar gas) contained a significant level of $\mathrm{NO}$, as much as the fraction in the large airways. Based on such evidence, it is reasonable to suggest that NOet represents alveolar NO and any changes in exhaled NO may reflect changes in NO diffusing into the blood. Indeed Hyde et al. [25] suggested that changes in NO in the exhaled gas represents changes in diffusing capacity rather than changes in NO production in the airways. Clini et al. [40] came to similar conclusions. Production of NO from lung tissue into the alveolar space is likely to increase during inflammatory conditions such as asthma, which can lead to increase NO in the exhaled air. However, it is also possible that diffusion of NO from the alveoli into the blood may have decreased in certain disease conditions such as interstitial lung disease, leading to more NO remaining in the alveolar space and hence to an increase in exhaled NO. During treatment the opposite happens. Therefore, changes in exhaled NO during inflammatory condition or during treatment may have to be explained partly in term of changes in diffusing capacity, or in ventilation/perfusion matching.

Chemiluminescence NO analyzers are the most accurate and rapid, but are not very portable and are relatively expensive. Less expensive and portable electrochemical analyzers are made by several companies, but have a low response time that would preclude using them for breath by breath analysis [41]. These portable analyzers were designed for a slow single breath maneuver, and are acceptable for offline mixed expired gas measurement. The results from such analyzer are thought to be poorly reproducible [18] most likely due to the poor reproducibility of the single slow deep breath maneuver. Some clinicians continue to question the suitability of $\mathrm{NO}$ measurement with such portable NO analyzers for clinical management $[19,42]$. This lack of confidence in the NO measurement may be partly due to the strict ATS guidelines which were improved in the updated version [14]. More consensus exist for the practice guidelines that were published to guide clinicians on interpretation and use of exhaled NO values [43]. These practice guidelines rely on having confidence in the measurement of exhaled $\mathrm{NO}$ and would be of greater clinical application only if we are able to measure exhaled NO more reliably. A better method is needed that is not so dependent on a strict methodology, requires no special effort and is easier to perform. Perhaps monitoring of NO, breath by breath, and using NOet is a better way to measure exhaled NO. A simple method such as using NOet as a measure of NO production in the lungs and airways, along with practice guidelines for interpretation of the results [43] would contribute significantly in improving confidence in using exhaled NO in routine clinical practice.

In conclusion, we believe that measuring end tidal NO to assess NO production from the lungs is simple and maybe more reliable than 
the single breath maneuver that is highly dependent on flow and is more difficult to perform. Although the differences between NOet and NOplat values were insignificant in healthy subjects, such differences have to be examined in patients with asthma or lung inflammation.

\section{Acknowledgement}

Supported by a grant from the American Heart Association and the Department of Anesthesiology.

\section{References}

1. Gustafsson LE, Leone AM, Persson MG, Wiklund NP, Moncada S (1991) Endogenous nitric oxide is present in the exhaled air of rabbits, guinea pigs and humans. Biochem Biophys Res Commun 181: 852-857.

2. Alving K, Weitzberg E, Lundberg JM (1993) Increased amount of nitric oxide in exhaled air of asthmatics. Eur Respir J 6: 1368-1370.

3. Kharitonov SA, Yates D, Robbins RA, Logan-Sinclair R, Shinebourne EA, et al. (1994) Increased nitric oxide in exhaled air of asthmatic patients. Lancet 343: 133-135.

4. Barnes PJ, Kharitonov SA (1996) Exhaled nitric oxide: a new lung function test Thorax 51: 233-237.

5. Barnes PJ, Dweik RA, Gelb AF, Gibson PG, George SC, et al. (2010) Exhaled nitric oxide in pulmonary diseases: a comprehensive review. Chest 138: 682692

6. Donohue JF, Jain N (2013) Exhaled nitric oxide to predict corticosteroid responsiveness and reduce asthma exacerbation rates. Respir Med 107: 943952.

7. Sandrini A, Taylor DR, Thomas PS, Yates DH (2010) Fractional exhaled nitric oxide in asthma: an update. Respirology 15: 57-70.

8. Byrnes CA, Dinarevic S, Busst CA, Shinebourne EA, Bush A (1997) Effect of measurement conditions on measured levels of peak exhaled nitric oxide. Thorax 52: 697-701.

9. Tsoukias NM, Tannous Z, Wilson AF, George SC (1998) Single-exhalation profiles of $\mathrm{NO}$ and $\mathrm{CO} 2$ in humans: effect of dynamically changing flow rate. $J$ Appl Physiol (1985) 85: 642-652.

10. Paraskakis E, Brindicci C, Fleming L, Krol R, Kharitonov SA, et al. (2006) Measurement of bronchial and alveolar nitric oxide production in norma children and children with asthma. Am J Respir Crit Care Med 174: 260-267.

11. Dinh-Xuan AT, Texereau J (1998) Measuring exhaled nitric oxide: not only a matter of how--but also why--should we do it? Eur Respir J 12: 1005-1007.

12. Kharitonov S, Alving K, Barnes PJ (1997) Exhaled and nasal nitric oxide measurements: recommendations. The European Respiratory Society Task Force. Eur Respir J 10: 1683-1693.

13. [No authors listed] (1999) Recommendations for standardized procedures for the on-line and off-line measurement of exhaled lower respiratory nitric oxide and nasal nitric oxide in adults and children-1999. This official statement of the American Thoracic Society was adopted by the ATS Board of Directors, July 1999. Am J Respir Crit Care Med 160: 2104-2117.

14. ATS/ERS recommendations for standardized procedure for the online and offline measurement of exhaled lower respiratory nitric oxide and nasal nitric oxide. 2005. Am J Respir Crit Care Med 171: 912-930.

15. Jöbsis Q, Schellekens SL, Kroesbergen A, Hop WC, de Jongste JC (1999) Sampling of exhaled nitric oxide in children: end-expiratory plateau, balloon and tidal breathing methods compared. Eur Respir J 13: 1406-1410.

16. Linn WS, Berhane KT, Rappaport EB, Bastain TM, Avol EL, et al. (2009) Relationships of online exhaled, offline exhaled, and ambient nitric oxide in an epidemiologic survey of schoolchildren. J Expo Sci Environ Epidemiol 19: 674-681.

17. Pendharkar S, Mehta S (2008) The clinical significance of exhaled nitric oxide in asthma. Can Respir J 15: 99-106.

18. Selby A, Clayton B, Grundy J, Pike K, Drew K, et al. (2010) Are exhaled nitric oxide measurements using the portable NIOX MINO repeatable? Respir Res 11: 43

19. Yeong KS, Kim SA, Suh C, Hyung KK, Lee CK, et al. (2014) A systemic review and meta-analysis of exhaled nitric oxide in chronic obstructive pulmonary disease: relationship to pulmonary function. Occup Environ Med 71: 118-119.
20. LaForce C, Brooks E, Herje N, Dorinsky P, Rickard K (2014) Impact of exhaled nitric oxide measurements on treatment decisions in an asthma specialty clinic Ann Allergy Asthma Immunol

21. Shaw DE, Berry MA, Thomas M, Green RH, Brightling CE, et al. (2007) The use of exhaled nitric oxide to guide asthma management: a randomized controlled trial. Am J Respir Crit Care Med 176: 231-237.

22. Cristescu SM, Mandon J, Harren FJ, Meriläinen P, Högman M (2013) Methods of NO detection in exhaled breath. J Breath Res 7: 017104

23. Tsoukias NM, Shin HW, Wilson AF, George SC (2001) A single-breath technique with variable flow rate to characterize nitric oxide exchange dynamics in the lungs. J Appl Physiol (1985) 91: 477-487.

24. Condorelli P, Shin HW, Aledia AS, Silkoff PE, George SC (2007) A simple technique to characterize proximal and peripheral nitric oxide exchange using constant flow exhalations and an axial diffusion model. J Appl Physiol (1985) 102: 417-425.

25. Hyde RW, Geigel EJ, Olszowka AJ, Krasney JA, Forster RE 2nd, et al. (1997) Determination of production of nitric oxide by lower airways of humans--theory. J Appl Physiol (1985) 82: 1290-1296.

26. Kharitonov SA, Barnes PJ (1997) Nasal contribution to exhaled nitric oxide during exhalation against resistance or during breath holding. Thorax 52: 540 544.

27. Tsujino I, Miyamoto K, Nishimura M, Shinano H, Kawakami Y (1999) Measurement of exhaled nitric oxide concentration using nasal continuous negative pressure. Respirology 4: 155-159.

28. Rutgers SR, Meijer RJ, Kerstjens HA, van der Mark TW, Koëter GH, et al. (1998) Nitric oxide measured with single-breath and tidal-breathing methods in asthma and COPD. Eur Respir J 12: 816-819.

29. Torretta S, Bossi A, Brevi A, Garavello W, lofrida E, et al. (2013) Headto-head comparison of single-breath and tidal-breath exhaled nitric oxide measurements. Pediatr Res 73: 221-225.

30. Franklin PJ, Turner SW, Mutch RC, Stick SM (2004) Comparison of singlebreath and tidal breathing exhaled nitric oxide levels in infants. Eur Respir J 23: $369-372$

31. Baraldi E, Azzolin NM, Dario C, Carra S, Ongaro R, et al. (1998) Effect of atmospheric nitric oxide (NO) on measurements of exhaled $\mathrm{NO}$ in asthmatic children. Pediatr Pulmonol 26: 30-34.

32. Silkoff PE, McClean PA, Slutsky AS, Furlott HG, Hoffstein E, et al. (1997) Marked flow-dependence of exhaled nitric oxide using a new technique to exclude nasal nitric oxide. Am J Respir Crit Care Med 155: 260-267.

33. Piacentini GL, Bodini A, Vino L, Zanolla L, Costella S, et al. (1998) Influence of environmental concentrations of $\mathrm{NO}$ on the exhaled NO test. Am J Respir Crit Care Med 158: 1299-1301.

34. Corradi M, Pelizzoni A, Majori M, Cuomo A, de' Munari E, et al. (1998) Influence of atmospheric nitric oxide concentration on the measurement of nitric oxide in exhaled air. Thorax 53: 673-676.

35. Hakim TS, Sugimori K, Camporesi EM, Anderson G (1996) Half-life of nitric oxide in aqueous solutions with and without haemoglobin. Physiol Meas 17 267-277.

36. Carlin RE, Ferrario L, Boyd JT, Camporesi EM, McGraw DJ, et al. (1997) Determinants of nitric oxide in exhaled gas in the isolated rabbit lung. Am J Respir Crit Care Med 155: 922-927

37. Cremona G, Higenbottam T, Takao M, Hall L, Bower EA (1995) Exhaled nitric oxide in isolated pig lungs. J Appl Physiol (1985) 78: 59-63.

38. Persson MG, Agvald P, Gustafsson LE (1994) Detection of nitric oxide in exhaled air during administration of nitroglycerin in vivo. Br J Pharmacol 111: 825-828.

39. Borland C, Cox Y, Higenbottam T (1993) Measurement of exhaled nitric oxide in man. Thorax 48: 1160-1162.

40. Clini E, Cremona G, Campana M, Scotti C, Pagani M, et al. (2000) Production of endogenous nitric oxide in chronic obstructive pulmonary disease and patients with cor pulmonale. Correlates with echo-Doppler assessment. Am J Respir Crit Care Med 162: 446-450.

41. Menzies D, Nair A, Lipworth BJ (2007) Portable exhaled nitric oxide measurement: Comparison with the "gold standard" technique. Chest 131 410-414. 
Citation: Hakim TS, Cremona G, Camporesi E (2014) Measurement of Exhaled Nitric Oxide Using End Tidal Value during Normal Breathing. J Pulm Respir Med 4: 219. doi:10.4172/2161-105X.1000219

42. Petsky HL, Cates CJ, Li A, Kynaston JA, Turner C, et al. (2009) Tailored interventions based on exhaled nitric oxide versus clinical symptoms for asthma in children and adults. Cochrane Database Syst Rev 7: 11-16.
43. Dweik R, Boggs PB, Erzurum SC, Irvin CG, Leigh MW, et al. (2011) An official ATS clinical practice guideline: Interpretation of exhaled nitric oxide levels (FENO) for clinical application. Am J Respi Crit Care Med 184: 602-615. 